\title{
A 5-year evaluation of chemoprophylactic treatment in elementary school children with subclinical leprosy
}

\author{
LINDA ASTARI $^{1-4}$, NASTITI INTAN PERMATA SARI ${ }^{5}$, KUSNARTEDJO NANANG $^{6}$, EDY CAHYONO $^{6}$, \\ NANNY HERWANTO ${ }^{2,3}$, MUHAMMAD YULIANTO LISTIAWAN ${ }^{2,3}$, DINAR ADRIATY ${ }^{4}$, \\ ISWAHYUDI ISWAHYUDI ${ }^{4}$, RATNA WAHYUNI ${ }^{4,7}$, MEDHI DENISA ALINDA ${ }^{2,3}$, \\ BAGUS HARYO KUSUMAPUTRA ${ }^{2,3}$, REGITA INDIRA AGUSNI ${ }^{2,3}$, INDROPO AGUSNI ${ }^{2-4}$, \\ SHINZO IZUMI ${ }^{4}$ and CITA ROSITA SIGIT PRAKOESWA ${ }^{2-4}$
}

\footnotetext{
${ }^{1}$ Doctoral Program of Medical Science; ${ }^{2}$ Department of Dermatovenereology, Faculty of Medicine, Universitas Airlangga, Surabaya, East Java 60131; ${ }^{3}$ Dr. Soetomo General Academic Hospital, Surabaya, East Java 60285;

${ }^{4}$ Institute of Tropical Disease, Universitas Airlangga, Surabaya, East Java 60115;

${ }^{5}$ Department of Biology, Faculty of Mathematics and Natural Sciences, Universitas Pertahanan, Bogor, West Java 16810;

${ }^{6}$ Sumberglagah Leprosy Hospital, Mojokerto, East Java 67152;

${ }^{7}$ Department of Health, Faculty of Vocational Studies, Universitas Airlangga, Surabaya East Java 60286, Indonesia
}

Received March 16, 2020; Accepted June 2, 2021

DOI: $10.3892 /$ br.2021.1464

\begin{abstract}
Subclinical leprosy is an infectious disease in which the immune system remains infected with Mycobacterium leprae (M. leprae). The progress of subclinical leprosy to clinical cases within 1 year of infection is $1.5 \%$, with an increase to $6 \%$ in the following 4 years. Rifampicin is frequently used for prevention of leprosy, and clarithromycin has a bactericidal effect on $M$. leprae. Thus, the combination of both is expected to improve disease control in patients with subclinical leprosy. The aim of the present study was to evaluate the efficacy of a chemoprophylactic treatment involving rifampicin and clarithromycin against subclinical leprosy in elementary school children from endemic areas of East Java over a 5-year period. The study was performed between 2011 and 2015. Samples were collected from 2,548 healthy elementary school children in Nguling (Pasuruan) and Raas (Sumenep), and analysed using ELISA for anti-PGL (phenolic glycolipid)-1 IgM antibodies. Children who were seropositive for anti-PGL-1 IgM antibodies received a chemoprophylactic regimen consisting of rifampicin (300 mg/day) and clarithromycin ( $250 \mathrm{mg} /$ day) daily for the initial 10 days, followed by the same regimen every 2 weeks for 3 months. Clinical and serological evaluations were performed annually for 5 years. Amongst the 2,548 healthy elementary school children,
\end{abstract}

Correspondence to: Professor Cita Rosita Sigit Prakoeswa, Department of Dermatovenereology, Faculty of Medicine, Universitas Airlangga, J1. Prof. Dr. Moestopo no. 47, Surabaya, East Java 60131, Indonesia

E-mail: cita-rosita@fk.unair.ac.id

Key words: Mycobacterium leprae, subclinical leprosy, clinical leprosy, clarithromycin, infectious disease
200 were seropositive. The anti-PGL-1 IgM antibody levels significantly decreased between 2011 and 2015 in Nguling (from $1,066.7$ to $137.4 \mathrm{U} / \mathrm{ml}$ ) and Raas (from 773.1 to $563.4 \mathrm{U} / \mathrm{ml}$ ), the levels decreased every year. In addition, the proportion of patients with decreased anti-PGL-1 IgM antibody levels was consistently higher than patients with increased anti-PGL-1 IgM antibody levels in all periods, except during 2013-2014, in Nguling and Raas. Chemoprophylactic treatment involving rifampicin and clarithromycin may thus be effective against subclinical leprosy amongst elementary school children.

\section{Introduction}

In 2015, Indonesia was amongst the three countries (along with India and Brazil) which reported $>10,000$ new leprosy cases, contributing to $8 \%$ of new cases globally. Amongst all new patients with leprosy in Indonesia, 10\% had already progressed to disability on diagnosis, and $11 \%$ were children (1). Leprosy in children is quite common in endemic countries. Moreover, $20-30 \%$ of patients with new cases exhibit neuritis and some are diagnosed with disability (2). The younger patients ( $<15$ years) show active circulation and transmission of Mycobacterium leprae (M. leprae) within the community, thus reflecting inefficiency in the national health system (3-5). With regard to leprosy in children, the most important matter is the prevention of disability and deformities by early detection and improved treatment of leprosy in leprosy endemic areas (6). Leprosy in children, particularly subclinical leprosy, may occur as currently, treatments are focused only on clinical leprosy, and subclinical leprosy is not a focus, even though patients with subclinical leprosy are sources of further infection.

A healthy individual exhibiting a sufficient immune response will typically attack an $M$. leprae infection; however, an individual with a compromised immune system may not be able to 
fend of the M.leprae infection appropriately, and this condition is considered subclinical leprosy (7). Subclinical leprosy can develop into clinical leprosy within 2-10 years, depending on the individual's immune status $(8,9)$. In 2008, the International Leprosy Congress (Hyderabad) showed that $1.5 \%$ of subclinical leprosy cases progress to clinical leprosy cases within 1 year, which increases to $6 \%$ in the following 4 years $(5,10,11)$. Thus, it is crucial to prevent the progression of subclinical leprosy to clinical leprosy, as the latter is more infectious and potentially more debilitating for the patient $(5,10,11)$. Using sensitive and specific screening tests is important to control transmission of leprosy. Serological tests have become the most common approach to detect subclinical infection $(5,10,11)$. PGL-1, a specific $M$. leprae cell wall antigen, is a popular antigen assessed for using antibodies, as its presence can be detected in the serum. Detection using these antibodies can be used for diagnosis, prediction of recurrence and identification of the risk of spreading the disease amongst individuals or within the community $(5,10,11)$. A meta-analysis by Penna et al (12) concluded that the risk of spreading from patients with clinical leprosy is $\sim 3 \mathrm{X}$ higher amongst patients positive for anti-PGL-1 antibodies than those who were negative for these antibodies. Furthermore, it has been shown that leprosy contacts $(13,14)$ and population (15) in an leprosy endemic area, with $\operatorname{IgM}$ anti-PGL-1 seropositivity have a 6-fold higher relative risk of becoming ill from leprosy in the 6-10 years of follow-up.

Various types of chemoprophylactic approaches have shown favourable results for prevention of leprosy infection or subclinical leprosy. In a previous study, intermittent dapsone administration for 2 years and intermittent acedapsone administration for 7 months reduced the risk of leprosy by 60 and $49 \%$, respectively (16). The single-dose rifampicin (SDR) chemoprophylactic regimen is currently being used in Indonesia, as well as in India, as well as several other ASEAN countries (17). However, this regimen has been shown to reduce the incidence of leprosy by only $57 \%$ (18). The efficacy of this regimen is more distinguished in distant contacts than in close contacts of index patients and may be associated with the bacillary load, which is supposedly higher in close contacts than in infrequent contacts $(19,20)$. Furthermore, studies have shown that SDR is effective for the prevention of leprosy only in those who receive a regimen; as such, SDR should be ideally administered to entire communities for it to exert an effect at the community level $(19,21)$. Therefore, early detection of index cases, increased coverage of SDR post-exposure prophylaxis (PEP), detection of subclinical leprosy followed by direct PEP and enhancement of the PEP regimen $\left(\mathrm{PEP}^{++}\right.$regimen) are required to improve prevention programs. The improved regimen is expected to be sufficiently effective for the treatment of patients with subclinical leprosy who possess a high bacillary load.

Clarithromycin exhibits a bactericidal effect on $M$. leprae and has an important role in the treatment of rifampicin-resistant leprosy (22-24). The pharmacokinetics are promising given its ability to penetrate well into macrophages and leukocytes $(4,25)$, which are the targets of $M$. leprae (5). Thus, a combination of clarithromycin and rifampicin may facilitate improved disease control in patients with subclinical leprosy.

The aim of the present study was to evaluate the efficacy of a chemoprophylactic treatment involving rifampicin and clarithromycin against subclinical leprosy in elementary school children from endemic areas in East Java (Indonesia) over a 5 -year period.

\section{Materials and methods}

Criteria. The primary criteria for the present study were as follows: High endemicity ( $\geq 250$ new cases per year in the last 3 years), epidemiological data available for at least the last 10 years, population not highly mobile, good collaboration with government health services, willingness to integrate prophylactic treatment involving leprosy health services, high logistical feasibility and good health infrastructure (including adequate leprosy services and contact screening).

Patients. The present study was performed annually between 2011 and 2015. Samples were collected from 2,548 healthy elementary school students who were not contacts of patients with leprosy. The students were recruited from several elementary schools in one area, but the school grades differed according to age. All students obtained consent from their parents to participate in the present study, and signed an informed consent form that clearly stated the purpose of the research, the method of sample collection, and the lack of risk from medical procedures. They also received an agreement form and resignation form. The present study was approved by the Ethical Committee in Health Research Unit of Dr. Soetomo General Hospital Surabaya, Indonesia (approval no. 30-511/H3.13/PPd/2012).

The recruited cohort consisted of 39 males and 59 females, and the age ranged from 7-14 years old. The regions from which patients were recruited were located in East Java, Indonesia; specifically, Nguling (Pasuruan) and Raas (Sumenep). Collection of samples in this study was performed by home visits during the 5 years of observation, and was completed using portable equipment. Peripheral blood samples were collected from one finger following disinfection. The collection of the blood used a capillary pipette; $100 \mu \mathrm{l}$ was collected, and this was then placed on a filter paper (Whatman, PLC; GE Healthcare Life Sciences; cat. no. 1442 110) until dry to avoid contaminants, such as fungi (26).

Serological test. The samples were analysed using indirect ELISA using anti-PGL-1 (NTP-BSA; cat. no. Nara XVII-48) according to the manufacturer's protocol for anti-PGL-1 IgM antibodies (27). A level of $605 \mathrm{U} / \mathrm{ml}$ or above was considered to indicate seropositivity. Antibody titres were classified as follows: $+1,605-1,000 \mathrm{U} / \mathrm{ml} ;+2,1,001-2,000 \mathrm{U} / \mathrm{ml}$; $+3,2,001-3,000 \mathrm{U} / \mathrm{ml}$; and $+4,>3,000 \mathrm{U} / \mathrm{ml}$.

Treatment regimens. Participants who were seropositive for anti-PGL-1 IgM antibodies received a chemoprophylactic regimen involving rifampicin (300 mg/day) and clarithromycin ( $250 \mathrm{mg} /$ day) every day for the initial 10 days and then received the same regimen every 2 weeks for 3 months. Evaluation of clinical and serological positivity was performed every year for 5 years $(28,29)$.

Data presentation. Descriptive analysis was used for the results of the present study. Data presentation was performed 
Table I. Mean of anti-PGL-1 IgM antibody levels in the children recruited from Nguling and Raas between 2011 and 2015.

\begin{tabular}{lcc}
\hline & \multicolumn{2}{c}{ Mean } \\
\cline { 2 - 3 } Year & Nguling & Raas \\
\hline 2011 & 1066,71875 & 773,123077 \\
2012 & 685,15625 & 560,923077 \\
2013 & 450,59375 & 281,276923 \\
2014 & 599 & 411,353846 \\
2015 & 137,4375 & 5,634 \\
\hline
\end{tabular}

using Microsoft Excel version 16.42 (Microsoft Corporation), and included frequency (raw data) and mean of the anti-PGL-1 levels (Table I).

\section{Results}

Among the 2,548 healthy elementary school children, 200 were seropositive ( 79 from Nguling and 121 from Raas). During the 5 years observation period only 98 (49\%) seropositive children had complete data; Nguling 41.8\% (33/79) and Raas $53.7 \%$ (65/121). In addition, certain children were lost after $>1$ follow-up visit and could not be contacted, or their home was in a difficult to reach location. Other children moved with their parents to another city. Overall, the prophylactic drugs were well tolerated, and few side effects associated with the drugs were reported. Notably, after the 5-years of observation, there were no children with subclinical leprosy that exhibited progression to clinical leprosy. The average of anti-PGL-1 IgM antibody levels decreased significantly between 2011 and 2015 in Nguling and Raas (from 1,066.72 to $137.44 \mathrm{U} / \mathrm{ml}$ and from 773.12 to $563.40 \mathrm{U} / \mathrm{ml}$, respectively). Using the antibody titres classification, the results showed that Nguling was seropositive +2 and Raas had seropositive +1 overall in 2011 .

The proportion of patients with decreased levels of anti-PGL-1 IgM antibody in Nguling and Raas was consistently higher than patients with increased levels of anti-PGL-1 IgM antibody in all periods, except during 2013-2014.

\section{Discussion}

Elimination of viable $M$. leprae in a population is a crucial step to reducing transmission. To be successfully eliminated, it is important to consider that viable $M$. leprae are present not only in individuals with clinical leprosy, but also in those who have subclinical leprosy. Unfortunately, its presence in individuals with subclinical leprosy is often undetected, as the current treatment approaches tend to focus on individuals with clinical leprosy. This phenomenon may explain why it has proven difficult to completely irradicate leprosy (16).

The present study evaluated the efficacy of a chemoprophylactic treatment regimen consisting of rifampicin and clarithromycin for 5 years. Early detection of subclinical leprosy can be performed using capillary blood and ELISA to determine the titre of anti-PGL-1 IgM antibody (21). The procedure was relatively easy, applicable and convenient for the participants. The samples can be dried and stored for a relatively long time prior to analysis or referral (21). Therefore, this procedure may be suitable to support the sustainability of early detection and prophylactic programmes. However, a previous study showed that anti-PGL-1 antibody was not an efficient predictor of contacts that may develop leprosy in endemic areas, and suggested that more specific biomarkers are required for early detection of leprosy (30). Another study showed that the sensitivity of anti-PGL-1 antibody for early detection of clinical leprosy was $<50 \%$, although the specificity was $80 \%$ (3). Nevertheless, as mentioned in a study by Barreto et al (3), several reports have found higher levels of anti-PGL-1 antibodies in children and young adults compared with older adults (3). Moreover, this previous study reported higher levels of anti-PGL-1 antibodies in children living in rural areas (considered to be busy areas facing food shortages) than in children living in high-income areas.

Previous studies on leprosy contacts $(13,14)$ or on blood donors representing the population of an endemic area in south eastern Brazil (15) found a 6-fold higher relative risk of illness in individuals who were IgM anti-PGL-1 seropositive. The present study showed a promising result of a decrease in the average levels of anti-PGL-1 IgM antibody every year for 5 years with prophylactic treatment. These results contradict the findings of Moet et al (18) who showed that chemoprophylactic treatment involving SDR had a protective effect only for the initial 2 years. In their initial 2-year follow-up, rifampicin prevented leprosy, particularly in individuals aged 10-14 and 20-29 years old. The difference in results may be related to the addition of clarithromycin. The present study used children who were not contacts of patients with leprosy, and the age range of the recruited cohort was 7-14 years old, all from an endemic area of leprosy. However, a previous study by Ghidar et al (31) showed that the addition of clarithromycin to a single-lesion therapy regimen did not increase cure rates (31). Nevertheless, at the 2-year follow-up, relapse rates were lower in the patients who received clarithromycin compared with those who did not; however, the difference was not significant. M. leprae is an obligate intracellular pathogen, which attacks macrophages for replication. A previous study on $M$. leprae-infected macrophages showed that invasion interferes with the activation of the cell-mediated immune responses that are required to attack $M$. leprae (32). Thus, the bactericidal activity of clarithromycin in macrophages can help improve the host's immune response, to reduce the amount of viable $M$. leprae and possibility of clinical leprosy.

Previous studies have shown that prophylactic treatment is very effective when given to the entire population, rather than only close contacts of patients with leprosy $(19,20)$. This may be related to the presence of viable $M$. leprae in undetected individuals or in those from untreated areas (20). However, favourable results were obtained in the present study, even though prophylactic treatment was only administered in a population of elementary school children.

A previous study in families of patients with leprosy treated with a multidrug treatment (MDT) regimen showed that several parents were not sufficiently educated. The drugs in the MDT regimen are usually taken by children, and it has been reported certain children are administered the incorrect 
drugs. Therefore, education of chemoprophylactic regimens for parents and teachers should be integrated into treatment programmes to promote a positive attitude and supportive environment for children (33).

The present study has some limitations. Specific doses of rifampicin and clarithromycin according to age and body weight were not used. The dosage used was based on the age range, as this method is easy but still valid when used in home visits. Treatment with specific doses may help optimize therapy and minimize side effects $(28,29)$.

In conclusion, the prophylactic treatment of children with subclinical leprosy showed good results over the 5 years evaluation period, and the prophylactic regimen used was well tolerated. After the 5-years of observation, there were no children with subclinical leprosy that exhibited progression to clinical leprosy, thus this regimen should be considered as a future prophylactic treatment for subclinical leprosy, particularly in children.

\section{Acknowledgements}

We would like to thank to Mr Sumarsono (Bachelor of Public Health) for assisting with the co-ordination of the present study.

\section{Funding}

The present study was funded by the East Java Provincial Government (grant no. 1.02-0106-22-005-5-2).

\section{Availability of data and materials}

The datasets used and/or analyzed during the present study are available from the corresponding author on reasonable request.

\section{Authors' contributions}

LA performed the analysis, and wrote and revised the manuscript based on suggestions from the other authors. NIPS contributed to study design, proofreading and manuscript revision. KN, EC, NH, MYL, DA, II, RW, MDA, BHK and RIA collected the samples and performed the measurements. IA, SI and CRSP contributed to study design, manuscript drafting and revision for intellectual content. All authors have read and approved the final manuscript. All authors confirm the authenticity of all the raw data.

\section{Ethics approval and consent to participate}

All students obtained consent from their parents to participate in the present study, and signed an informed consent form that clearly stated the purpose of the research, the method of sample collection, and the lack of risk from medical procedures. They also received an agreement form and resignation form. The present study was approved by the Ethical Committee in Health Research Unit of Dr. Soetomo General Hospital Surabaya, Indonesia (approval no. 30-511/H3.13/PPd/2012).

\section{Patient consent for publication}

Not applicable.

\section{Competing interests}

The authors declare that they have no competing interests.

\section{References}

1. WHO: Weekly Epidemiological Report. WHO 91: 405-420, 2016.

2. Butlin CR and Saunderson P: Children with leprosy. Lepr Rev 85: 69-73, 2014.

3. Barreto JG, Guimarães Lde S, Frade MA, Rosa PS and Salgado CG: High rates of undiagnosed leprosy and subclinical infection amongst school children in the Amazon region. Mem Inst Oswaldo Cruz 107 (Suppl 1): S60-S67, 2012.

4. Oliveira MBB and Diniz LM: Leprosy among children under 15 years of age: Literature review. An Bras Dermato 91: 196-203, 2016.

5. Lourenco DSD, Campelo TA, Cruz GA, De Almeida PC, Sa Goncalves HD, Pontes MADA, Lima LNGC and Frota CC: Detection of subclinical Mycobacterium leprae infection in children, contacts of leprosy cases, Fortaleza-Ceara', Brazil. Lepr Rev 88: 184-196, 2017.

6. Adriaty D, Sp CR, Iswahyudi, Wahyuni R, Agusni I and Izumi S: Leprosy transmission in endemic and non-endemic areas based on the profile of antibody response of PGL-1 and PCR detection of Mycobacterium leprae DNA from nasal swab among healthy children of East Java, Indonesia. Infec Dis Rep 12 (Suppl 1): S8748, 2020.

7. Fine PE: Leprosy: The epidemiology of a slow bacterium. Epidemiol Rev 4: 161-188, 1982.

8. Van Beers SM, de Wit MY and Klatser PR: The epidemiology of Mycobacterium leprae: Recent insight. FEMS Microbiol Lett 136: 221-230, 1996.

9. Hooij AV and Geluk A: Immunodiagnostic for leprosy. In: International Textbook of Leprosy. Scollard D and Gillis T (eds). American Leprosy Missions, pp. 2-3, Leiden, The Netherlands, 2016.

10. Moura RS, Calado KL, Oliveira ML and Bührer-Sékula S: Leprosy serology using PGL-1: A systematic review. Rev Soc Bras Med Trop 41 (Suppl 2); S11-S18, 2008.

11. Araújo S, Lobato J, Reis Éde M, Souza DO, Gonçalves MA, Costa AV, Goulart LR and Goulart IM: Unveiling healthy carriers and subclinical infections among household contacts of leprosy patients who play potential roles in the disease chain of transmission. Mem Inst Oswaldo Cruz 107 (Suppl 1): S55-S59, 2012.

12. Penna ML, Penna GO, Iglesias PC, Natal S and Rodrigues LC: Anti-PGL-1 positivity as a risk marker for the development of leprosy among contacts of leprosy cases: Systematic review and meta-analysis. PLoS Negl Trop Dis 10: e0004703, 2016.

13. Araujo S, Rezende MM, Sousa DC, Rosa MR, Santos DC, Goulart LR and Goulart IMB: Risk-benefit assessment of Bacillus Calmette-Guérin vaccination, anti-phenolic glycolipid I serology, and Mitsuda test response: 10-year follow-up of household contacts of leprosy patients. Rev Soc Bras Med Trop 48: 739-745, 2015.

14. Araújo S, Freitas LO, Goulart LR and Goulart IMB: Molecular evidence for the aerial route of infection of Mycobacterium leprae and the role of asymptomatic carriers in the persistence of leprosy. Clin Infect Dis 63: 1412-1420, 2016.

15. Goulart IM, Araújo S, Filho AB, de Paiva PH and Goulart LR: Asymptomatic leprosy infection among blood donors may predict disease development and suggests a potential mode of transmission. J Clin Microbiol 53: 3345-3348, 2015.

16. Reveiz L,Buendía JA and Téllez D: Chemoprophylaxis in contacts of patients with leprosy: Systematic review and meta-analysis. Rev Panam Salud Publica 26: 341-349, 2009.

17. Barth-Jaeggi T, Steinmann P, Mieras L, van Brakel W, Richardus JH, Tiwari A, Bratschi M, Cavaliero A, Vander Plaetse B, Mirza F, et al: Leprosy Post-Exposure Prophylaxis (LPEP) programme: Study protocol for evaluating the feasibility and impact on case detection rates of contact tracing and single dose rifampicin. BMJ Open 6: e013633, 2016.

18. Moet FJ, Pahan D, Oskam L and Richardus JH; COLEP Study Group: Effectiveness of single dose rifampicin in preventing leprosy in close contacts of patients with newly diagnosed leprosy: Cluster randomised controlled trial. BMJ 336: 761-764, 2008.

19. Bakker MI, Hatta M, Kwenang A, Van Benthem BH, Van Beers SM, Klatser PR and Oskam L: Prevention of leprosy using rifampicin as chemoprophylaxis. Am J Trop Med Hyg 72: 443-448, 2005 . 
20. Smith WC and Aerts A: Role of contact tracing and prevention strategies in the interruption of leprosy transmission. Lepr Rev 85: 2-17, 2014.

21. Feenstra SG, Pahan D, Moet FJ, Oskam L and Richardus JH: Patient-related factors predicting the effectiveness of rifampicin chemoprophylaxis in contacts: 6 year follow up of the COLEP cohort in Bangladesh. Lepr Rev 83: 292-304, 2012.

22. Ji B, Jamet P, Perani EG, Bobin P and Grosset JH: Powerful bactericidal activities of clarithromycin and minocycline agains Mycobacterium leprae in lepromatous leprosy. J Infect Dis 168 188-190, 1993

23. WalkerLL, VanLandinghamRMandShinnickTM:Clarithromycin is bactericidal against strains of Mycobacterium leprae resistant and susceptible to dapsone and rifampin. Int J Lepr Other Mycobact Dis 61: 59-65, 1993.

24. Lazo-Porras M, Prutsky GJ, Barrionuevo P, Tapia JC, Ugarte-Gil C, Ponce OJ, Acuña-Villaorduña A, Domecq JP, De la Cruz-Luque C, Prokop LJ and Málaga G: World health organization (WHO) antibiotic regimen against other regimens for the treatment of leprosy: A systematic review and meta-analysis. BMC Infect Dis 20: 62, 2020.

25. Lebel M: Pharmacokinetic properties of clarithromycin: A comparison with erythromycin and azithromycin. Can J Infect Dis 4: 148-152, 1993.

26. Crowther JR: The ELISA guidebook. Methods Mol Biol 149: III-IV, 1-413, 2000.
27. Mieras LF, Taal AT, van Brakel WH, Cambau E, Saunderson PR, Smith WCS, Prakoeswa CRS, Astari L, Scollard DM, do Nascimento DC, et al: An enhanced regimen as post-exposure chemoprophylaxis for leprosy: PEP+. BMC Infect Dis 18: 506, 2018

28. MIMS: Drug information. Accessed: April 18, 2021. https://www. mims.com/indonesia.

29. Grüner N, Stambouli O and Ross RS: Dried blood spots-preparing and processing for use in immunoassays and in molecular techniques. J Vis Exp 97: 52619, 2015.

30. Richardus RA, van der Zwet K, van Hooij A, Wilson L, Oskam L, Faber R, van den Eeden SJF, Pahan D, Alam K, Richardus JH and Geluk A: Longitudinal assessment of anti-PGL-1 serology in contacts of leprosy patients in Bangladesh. PLoS Negl Trop Dis 11: e0006083, 2017.

31. Girdhar A, Kumar A and Girdhar BK: A randomised controlled trial assessing the effect of adding clarithromycin to rifampicin, ofloxacin and minocycline in the treatment of single lesion paucibacillary leprosy in Agra District, India. Lepr Rev 82: 46-54, 2011.

32. Yang D, Shui T, Miranda JW, Gilson DJ, Song Z, Chen J, Shi C, Zhu J, Yang J and Jing Z: Mycobacterium leprae-infected macrophages preferentially primed regulatory $\mathrm{T}$ cell responses and was associated with lepromatous leprosy. PLoS Negl Trop Dis 10: e0004335, 2016.

33. Lal V, Pal S, Haldar NK, Mandal PK and Srinivas G: What parents should know while their child is on MDT: Insights from a qualitative study in Eastern India. Lepr Rev 85: 81-84, 2014. 